\title{
Correction to: A novel method for assessing climate change impacts in ecotron experiments
}

\author{
Inne Vanderkelen ${ }^{1}$ (D) - Jakob Zscheischler ${ }^{2,3} \cdot$ Lukas Gudmundsson $^{4} \cdot$ Klaus Keuler $^{5}$ • Francois Rineau ${ }^{6}$. \\ Natalie Beenaerts ${ }^{6} \cdot$ Jaco Vangronsveld $^{6,7} \cdot$ Sara Vicca $^{8} \cdot$ Wim Thiery ${ }^{1,4}$
}

Received: 17 July 2020 / Revised: 20 July 2020 / Accepted: 20 July 2020 / Published online: 3 August 2020

(C) ISB 2020

\section{Correction to: International Journal of Biometeorology https://doi.org/10.1007/s00484-020-01951-8}

The article was published bearing a typographical error to the second author name listed. The author group regrets the error and the name should be referenced and credited as Jakob Zscheischler and not the former.

In addition, the citation Zscheischler J., Westra S., van den Hurk B. J. J. M., Seneviratne S. I., Ward P. J., Pitman A., AghaKouchak A., Bresch D. N., Leonard M., Wahl T., Zhang X. (2018) "Future climate risk from compound events" should be recognized as Zscheischler J., Westra S., van den Hurk B. J. J. M., Seneviratne S. I., Ward P. J., Pitman A., AghaKouchak A., Bresch D. N., Leonard M., Wahl T., Zhang X. (2018) "Future climate risk from compound events". Nature Clim Change 8, 469-477 (2018). https://doi. org/10.1038/s41558-018-0156-3.

This correction stands to correct the original article.

The online version of the original article can be found at https://doi.org/10. 1007/s00484-020-01951-8

Inne Vanderkelen

inne.vanderkelen@vub.be

1 Department of Hydrology and Hydraulic Engineering, Vrije Universiteit Brussel, Brussels, Belgium

2 Climate and Environmental Physics, University of Bern, Bern, Switzerland

3 Oeschger Center for Climate Change Research, University of Bern, Bern, Switzerland
Institute for Atmospheric and Climate Science, ETH Zurich, Zurich, Switzerland

5 Department of Environmental Meteorology, Brandenburg University of Technology Cottbus-Senftenberg, Cottbus, Germany

6 Centre for Environmental Sciences, UHasselt, Hasselt, Belgium

7 Department of Plant Physiology, Faculty of Biology and Biotechnology, Maria Curie-Sklodowska University, Lublin, Poland

8 Department of Biology, University of Antwerp, Wilrijk, Belgium 